\title{
Os Indicadores da Qualidade na Educação Infantil e a política de avaliação $^{1}$
}

\author{
Valéria Virgínia Lopes* \\ Ananda Grinkraut**

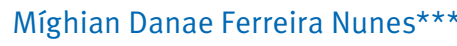

*Doutora emEducaçãopelaFaculdade de Educação da USP. Coordenou a execução do Monitoramento do Uso dos Indicadores da Qualidade na Educação Infantil, pela Ação Educativa

E-mail:vavlopes@gmail.com

**Mestre em Educação pela Faculdade de Educação da Unicamp. É assessora do programa Diversidade, raça e participação da Ação Educativa, atua e pesquisa na área do direito à educação e políticas educacionais

E-mail:_ananda.grinkraut@ acaoeducativa.org

***Mestre em Educação pela Faculdade de Educação da USP. Foi pesquisadora do programa Indicadores da Qualidade na Educação Infantil, pela Ação Educativa, e atua na área da educação infantil e relações etnicorraciais

E-mail:mighiandanae@yahoo.com.br
Resumo: Os Indicadores da Qualidade na Educação Infantil foram lançados em 2009 e distribuídos pelo Ministério da Educação em todos os estados e municípios brasileiros. 0 monitoramento de sua utilização, realizado em 2011/12, identificou seu grande potencial como instrumento de autoavaliação das unidades educacionais e como mecanismo de apoio às políticas públicas da educação. Visando aprimorar o uso dos Indicadores e, ainda, contribuir na formulação de uma política de avaliação nacional na/da educação infantil, tal como definida no Plano Nacional de Educação (2014-2024), um grupo de trabalho composto por representantes do MEC, do Unicef, da Undime e da Ação Educativa organizou uma proposta de uso acompanhado dos Indicadores em um município paulista. Aqui, apresentam-se as premissas que nortearam a proposição e as etapas de desenvolvimento dessa proposta.

Palavras-chave: Educação Infantil. Avaliação. Qualidade. Participação

A versão preliminar do texto "Proposta de uso dos Indicadores da Qualidade na Educação Infantil na política de avaliação na/da Educação Infantil” foi elaborada pela Ação Educativa e submetida para aprimoramento ao grupo coordenador nacional e ao grupo técnico dos Indicadores da Qualidade na Educação Infantil. A proposta foi elaborada no marco do projeto "O uso dos Indicadores da Qualidade na Educação e os Planos de Educação", dialogando fortemente com as proposições contidas na Iniciativa De Olho nos Planos (www.deolhonosplanos. org.br). 0 projeto conta com o apoio do Unicef e é coordenado por Denise Carreira. 


\section{INTRODUÇÃO}

A centralidade da avaliação na educação básica e no ensino superior nos últimos quase 25 anos chegou, também, às políticas públicas da educação infantil. A aprovação do Plano Nacional de Educação, no dia 25 de junho de 2014, evidencia essa tendência ao prever como uma das estratégias da meta referente à educação infantil (meta 1) a implementação da avaliação dessa etapa da educação básica, a ser realizada a cada dois anos, com base em parâmetros de qualidade (Lei 13.005/2014, art. 1ํ, estratégia 1.6). Essa estratégia revela um debate que já vinha ocorrendo no âmbito das políticas públicas e das pesquisas, com a participação de organizações da sociedade civil.

Muitas têm sido as discussões e polêmicas na formulação de uma proposta de avaliação da educação infantil, que refletem diferentes concepções de infância, do direito à educação nessa faixa etária e de qualidade.

No contexto desse debate, duas instâncias foram criadas em âmbito nacional para debater e apresentar propostas para a avaliação da educação infantil: um grupo de trabalho constituído pelo Ministério da Educação (MEC) em 2012, e um pelo Instituto Nacional de Estudos e Pesquisas Educacionais Anísio Teixeira (Inep), em 2013, para apresentar, respectivamente, subsídios e propor uma política nacional de avaliação da educação infantil.

Uma das recomendações apresentadas pelo referido Grupo de Trabalho/MEC diz respeito diretamente ao uso dos Indicadores da Qualidade na Educação Infantil ${ }^{2}$, publicação lançada em 2009, produzida numa parceria entre o MEC, o Unicef, a Undime, a Ação Educativa e a Fundação Orsa e distribuída, pelo MEC, em todo o país:

Para construir uma cultura de avaliação na e da educação infantil e fortalecer a concepção de avaliação participativa associada à definição de um conjunto de indicadores de gestão educacional, cabe ao MEC/SEB divulgar amplamente padrões de qualidade, a partir dos Indicadores da Qualidade na Educação Infantil, assegurando sistemática de envolvimento do órgão executivo do respectivo sistema de ensino (MINISTÉRIO DA EDUCAÇÃO, 2012, p. 26).

Os Indicadores foram distribuídos em todo o Brasil e, em 2011, foi realizado o Monitoramento de sua utilização ${ }^{3}$. Dentre as revelações do Monitoramento

2 Os Indicadores da Qualidade na Educação Infantil se constituem como um instrumento de autoavaliação participativa de unidades de educação infantil e serão abordados na próxima seção deste texto.

3 O monitoramento do uso dos Indicadores da Qualidade na Educação Infantil é abordado na terceira seção deste artigo, ao se abordarem os fundamentos da proposta de uso desse instrumento na política de avaliação da e na educação infantil. 
destaca-se a disseminação e variedade de usos por secretarias de educação em todo o país.

A partir dos resultados do Monitoramento, foi proposto o uso dos Indicadores da Qualidade na Educação Infantil - formulado originalmente para a autoavaliação participativa de unidades de educação infantil - para contribuir com a construção de uma política de avaliação na e da educação infantil. Pretende-se, assim, colocá-lo num outro âmbito de inserção e organizar subsídios para as políticas públicas.

Essa proposta de uso dos Indicadores da Qualidade na Educação Infantil está sendo desenvolvida, de forma acompanhada, em um município paulista, visando, por um lado, aprimorar a política de educação infantil do município em questão e, por outro, proporcionar subsídios para o debate e possível formulação de uma política nacional de avaliação da/na educação infantil.

Este artigo tem como objetivo apresentar os fundamentos que embasaram a construção da proposta de uso dos Indicadores e as etapas previstas para seu acompanhamento junto ao município. 0 artigo está organizado em três partes. A primeira apresenta o contexto da avaliação da/na educação infantil, resgatando a legislação nacional e as principais tensões hoje existentes nesse campo. Os fundamentos que embasaram a proposta de uso dos Indicadores da Qualidade na Educação Infantil na avaliação da/na política de educação infantil são apresentados na segunda parte e, em seguida, são abordadas as etapas que constituem a proposta metodológica em andamento em um município paulista.

CONTEXTO, TENSÕES E PROPOSTAS DE AVALIAÇÃO DA/NA EDUCAÇÃO INFANTIL

A avaliação da educação infantil - diferentemente dos demais níveis da educação básica e do ensino superior - até recentemente não estava contemplada nas políticas nacionais de avaliação externa. As políticas de avaliação externa nacionais, que desde a década de 1990 têm ocupado uma posição central na definição e implementação da política educacional brasileira, não abarcavam a avaliação de creches ou de pré-escolas.

No entanto, isso não fez com que a avaliação não estivesse presente na educação infantil. Segundo Rosemberg (2013), “desde há muito, na educação infantil, avalia-se e trata-se da avaliação, mas não de modo recortado, denominado e enquadrado como um problema social, demarcando campo de conhecimento e ação política e, consequentemente, território em disputa” ( $p$. 
48). Ao considerarmos que a avaliação é um procedimento intrínseco à ação política, sua utilização não é exclusividade do atual momento histórico. Um dos aspectos que a diferencia nas últimas décadas tem sido seu uso voltado à “direção remota” das políticas governamentais, além de uma revisão do seu próprio significado (FREITAS, 2005).

Apesar de até o momento a educação infantil não contar com uma política nacional de avaliação, preocupações tem sido evidenciadas, alertando para que modelos hegemônicos presentes nos demais níveis de ensino não sejam transpostos para a educação infantil (CORRÊA; ANDRADE, 2011; MORO, 2013; ROSEMBERG, 2013). Veremos a seguir como esse assunto é abordado na legislação brasileira e, em seguida, quais são as principais tensões presentes nesse campo.

No âmbito legal, a avaliação na educação infantil foi explicitada pela primeira vez em 1996, na Lei de Diretrizes e Bases da Educação Nacional (Lei 9.394), compreendida como uma das regras comuns que organizam a educação infantil e deve ser realizada "mediante acompanhamento e registro do desenvolvimento das crianças, sem o objetivo de promoção, mesmo para 0 acesso ao ensino fundamental" (art. 31, inciso I).

É importante destacar que já no Estatuto da Criança e do Adolescente (Lei 8.069/1990) foi assegurado no artigo referente à educação, o “direito [das crianças e adolescentes] de contestar critérios avaliativos, podendo recorrer às instâncias escolares superiores" e o "direito dos pais ou responsáveis ter ciência do processo pedagógico, bem como participar da definição das propostas educacionais" (art. 53, inciso III e parágrafo único).

Em 2009, as Diretrizes Curriculares Nacionais (Resolução 5 do Conselho Nacional de Educação) reafirmaram esses direitos previstos no ECA, ao orientar que a proposta pedagógica das instituições de educação infantil deve assegurar "a participação, o diálogo e a escuta cotidiana das famílias, o respeito e a valorização de suas formas de organização" e “o estabelecimento de uma relação efetiva com a comunidade local e de mecanismos que garantam a gestão democrática e a consideração dos saberes da comunidade”, dentre outros princípios (art. 8, parágrafo 1ํㅡㄹ incisos III e IV).

Além disso, no que se refere à avaliação, as Diretrizes especificaram o que estava previsto na LDB, realizando uma sutil modificação que abre espaço para grandes mudanças: em seu décimo artigo, estabelecem que "As instituições de Educação Infantil devem criar procedimentos para acompanhamento do 
trabalho pedagógico e para avaliação do desenvolvimento das crianças, sem objetivo de seleção, promoção ou classificação". Enquanto a LDB define a avaliação "mediante acompanhamento e registro do desenvolvimento da criança”, as Diretrizes indicam a criação de procedimentos "para avaliação do desenvolvimento das crianças". Essas formulações podem resultar em processos e procedimentos bastante diferentes: a primeira, em instrumentos de acompanhamento e registro; a segunda, de atribuição de valor, de julgamento. Ainda que as Diretrizes ressaltem aspectos a serem garantidos nesse processo, tais como a variedade de registros utilizados e a apresentação de documentação específica às famílias, para que essas conheçam o trabalho da instituição, bem como acompanhem o desenvolvimento e aprendizado da criança, as tensões e disputas no campo da avaliação na/da educação infantil ganham mais fôlego e legitimidade.

O Plano Nacional de Educação, além de estabelecer um Sistema Nacional de Avaliação da Educação Básica que proporcione informações para “a avaliação da qualidade da educação básica e para a orientação das políticas públicas desse nível de ensino" (Lei 13.005, 2014, art. 11), também previu, conforme já mencionado, a implantação da avaliação da educação infantil, com o objetivo de "aferir a infraestrutura física, o quadro de pessoal, as condições de gestão, os recursos pedagógicos, a situação de acessibilidade” (Estratégia 1.6).

Apesar da política de avaliação da educação infantil ter sido prevista legalmente apenas na formulação do atual PNE, em 2010, a proposta de uso de uma escala estadunidense nas unidades de educação infantil brasileiras ${ }^{4}$ fomentou um importante debate, evidenciando que as tensões em relação à avaliação na/da educação expressam-se de diferentes modos. Vários artigos e posicionamentos (GT 07 ANPED, 2011; MIEIB, 2011) foram divulgados buscando incidir nesse debate, considerando já naquele momento a iminência da aprovação do PNE e em que medida essa discussão interferiria em seu conteúdo.

A avaliação da educação infantil, com base no uso do teste psicológico denominado Ages \& Stages Questionnaires (ASQ), foi proposta pela Secretaria de Assuntos Estratégicos da Presidência da República para avaliar o desenvolvimento das crianças na educação infantil, a partir da experiência da Prefeitura do Rio de Janeiro. Esse teste avalia crianças entre 1 mês e 5,5

4 A ASQ (Ages \& Stages Questionnaires) foi apresentada pela Secretaria de Assuntos Estratégicos da Presidência da República, para debate nacional, como uma proposta de avaliação do desenvolvimento das crianças na educação infantil. Disponível em: < http:// www.sae.gov.br/site/?p=9623>. Acesso em: 20 jul. 2014. 
anos, em cinco áreas de desenvolvimento, com o objetivo de "detectar, o mais rápido possível, a normalidade do desenvolvimento global das crianças e, consequentemente, atrasos no desenvolvimento infantil” (NEVES; MORO, 2013, p. 275-276).

Essa proposta foi duramente criticada por pesquisadores e educadores da área da educação infantil. Moro (2013) elenca várias dessas preocupações, iniciando pelo foco da avaliação no desenvolvimento da criança, sem se considerar o contexto e as condições em que o direito à educação é oferecido. A forma e o tempo previstos para a aplicação também foram alvos de críticas: ao possibilitar que o teste fosse aplicado por qualquer adulto, sem formação específica e considerando que é um teste psicológico, que afere o desenvolvimento da criança, a primeira fragilidade se evidencia, uma vez que tal teste deveria ser aplicado por profissionais qualificados. A possibilidade de estigmatizar as crianças com base nos resultados oriundos desse tipo de avaliação é também apontada, na medida em que "a adoção de instrumentos como o teste ASQ-3 reitera uma concepção de criança abstrata e ideal, o que não favorece uma reflexão acerca da criança inserida em um contexto histórico, social e cultural” (NEVES; MORO, 2013, p. 287). Nesse sentido, conforme Rosemberg (2013), esse risco de estigmatização das crianças e construção de profecias autorrealizadoras relaciona-se a uma questão ética, que precisaria ser mais bem discutida e evidenciada nesse tipo de avaliação. Para a autora, seria fundamental que essas avaliações tratassem melhor da confidencialidade das informações, bem como dos usos feitos com base em seus resultados, lembrando que inúmeras pesquisas têm utilizado as creches como "celeiro de sujeitos" para obtenção de dados em diversas áreas do conhecimento.

Para Corrêa e Andrade (2011), é possível verificar uma associação entre a adoção desse tipo de instrumento com a manutenção de condições precárias no atendimento à primeira infância ao não pressupor, na avaliação, a existência de uma escola de educação infantil, nem de profissionais formados para o magistério. Assim, segundo as autoras, trata-se "de uma defesa do atendimento pobre para pobres também quando se propõe determinado tipo de instrumento de avaliação" (p. 277).

Destaca-se, também, a ausência nesse tipo de avaliação de reflexões sobre as políticas públicas de educação infantil: sua organização, gestão, condições de funcionamento, de trabalho dos profissionais, dentre outras, bem como as possíveis consequências de sua adoção no cotidiano das creches e pré- 
escolas (NEVES; MORO, 2013). Nesse sentido, vale lembrar críticas feitas, ainda na década de 1990, às avaliações voltadas ao ensino fundamental e ensino médio, com foco apenas no rendimento escolar dos estudantes: “mesmo partindo da constatação de que é necessário compreender os problemas e sucessos que a realidade brasileira apresenta, consideramos temerário um sistema de avaliação cujo indicador nuclear seja o rendimento do aluno" (SOUSA, 1997, p. 279).

Com base nas críticas apontadas a uma avaliação com foco na criança, vários foram os posicionamentos a favor da adoção de instrumentos avaliativos que conciliem dados de contexto e das condições de atendimento das unidades de educação infantil (MEC, 2012; MORO, 2013), dentre eles, os Indicadores da Qualidade na Educação Infantil, distribuídos pelo MEC em todos os estados e municípios brasileiros.

Os Indicadores da Qualidade na Educação Infantil constituem-se em uma proposta de autoavaliação participativa das unidades educacionais que visa orientar e apoiar o trabalho nessa etapa da educação básica. Esse instrumento foi elaborado a partir de um processo participativo e democrático que envolveu pesquisadores, gestores e educadores ligados a essa etapa de ensino e ativistas do Movimento Interfóruns de Educação Infantil do Brasil (Mieib) 5 .

Além de apresentar sugestões de procedimentos para a organização e condução da autoavaliação, o material organiza a avaliação em sete dimensões de qualidade, sendo essas (BRASIL, 2009)6:

- planejamento institucional (proposta pedagógica, registro e indicativos sobre as práticas);

- multiplicidade de experiências e linguagens (reflexões sobre a rotina e práticas adotadas para incentivar a autonomia das crianças; formas de a criança conhecer e experimentar o mundo e se expressar);

- interações (espaço coletivo de convivência e respeito);

- promoção da saúde (reflexões sobre práticas e condutas cotidianas adequadas para a prevenção de acidentes, os cuidados com a higiene e a alimentação saudável para cada grupo de idade);

- espaços, materiais e mobiliários (reflexões sobre a disposição e

5 Essa publicação, lançada em 2009, foi elaborada sob a coordenação conjunta do Ministério da Educação (MEC), da Ação Educativa, da Fundação Orsa, da Undime e do Unicef, sendo que mais de 300 mil exemplares do material foram distribuídos, pelo MEC, para as instituições de educação infantil do país.

6 BRASIL. Indicadores da Qualidade na Educação Infantil. Brasília: MEC/SEB, 2009. 
disponibilidade de materiais, espaços e mobiliários de maneira a atender às múltiplas necessidades de adultos e crianças);

- formação e condições de trabalho das professoras e demais profissionais (reflexões sobre a formação inicial e continuada, condições de trabalho adequadas às múltiplas tarefas, natureza da relação entre instituição e comunidade);

- cooperação e troca com as famílias e participação na rede de proteção social (reflexões sobre os processos de socialização, as brincadeiras e a convivência com a diversidade).

Os Indicadores têm sido considerados uma importante ferramenta para a avaliação na educação infantil por orientar estratégias coletivas de trabalho nas unidades escolares; proporcionar a participação dos vários segmentos envolvidos com o processo educacional na negociação e construção de uma concepção de qualidade, fortalecendo a gestão democrática na educação; além de desencadear processos formativos dos sujeitos com a sua efetivação (MEC et. al., 2013; RIBEIRO, 2013).

A metodologia proposta por esse instrumento pressupõe a realização de uma autoavaliação institucional das unidades de educação infantil, isto é, a análise da instituição educativa pelos próprios sujeitos que constroem e usufruem do atendimento, nas suas várias dimensões: "político, pedagógica e administrativa", e "tem como marco o projeto pedagógico e visa subsidiar seu contínuo aprimoramento" (MEC, 2012, p. 15).

Avaliar a qualidade de um determinado atendimento - no caso aqui abordado, a educação infantil - por meio de um processo de autoavaliação participativa parte do pressuposto de que qualidade não é um valor absoluto. Seu significado varia conforme o uso, a finalidade, além da visão de mundo, sociedade e educação de quem o usa (SOUSA, 1997; BERAZA, 2013). Conforme explicitado por Sousa (1997), parte-se do seguinte conceito de qualidade:

Qualidade não é "algo dado", não existe "em si", remetendo à questão axiológica, ou seja, dos valores de quem produz a análise da qualidade. A emergência de critérios de avaliação não se dá de modo dissociado das posições, crenças, visão de mundo e práticas sociais de quem os concebe. É um conceito que nasce da perspectiva filosófica, social, política de quem faz o julgamento e dela é expressão. Portanto, os enfoques e critérios assumidos em um processo avaliativo revelam as opções axiológicas dos que dele participam (p. 267). 
Pode-se exemplificar essa concepção de qualidade com os resultados obtidos na consulta ${ }^{7}$ realizada justamente sobre esse tema na educação infantil ${ }^{8}$, com professores(as), funcionários(as), diretores(as) e/ou coordenadores(as), mães e pais usuários, mães e pais não usuários, líderes da comunidade e crianças que estavam frequentando as creches e pré-escolas em quatro estados brasileiros. Dentre os resultados observados, destaca-se a diferença entre os atributos que conferem qualidade à creche e à pré-escola, reconhecidos, por exemplo, pelas famílias pobres e pelas professoras:

Mães/pais mais pobres desejam que as instituições de educação infantil ofereçam alimentação e cuidados com a saúde. Já as professoras manifestam preocupação com sua própria formação e com o projeto pedagógico, mesmo sem mencionar o currículo e o desenvolvimento de projetos (CAMPANHA, MIEIB, 2011, p. 44).

Nota-se, portanto, que a qualidade é um conceito que varia conforme a situação, o contexto social e os interesses de quem avalia. Considerando as especificidades da educação infantil e a fundamental relação entre as instituições e as famílias no atendimento às crianças, a avaliação desse atendimento e os critérios de qualidadeestão sujeitos a constantes negociações. A metodologia proposta nos Indicadores proporciona a explicitação dessas tensões, a construção de consensos - ainda que provisórios - e a formulação de estratégias e ações para aprimorar a qualidade negociada.

Vale destacar que se esse processo proporciona a formação dos sujeitos envolvidos (CAMPANHA, MIEIB, 2011; RIBEIRO, 2013), concomitantemente qualifica a demanda pelo direito à educação infantil.

Nesse sentido, é interessante observar a definição de escolas de qualidade apresentada por Beraza (2013), que não dependem apenas das condições materiais, mas também dos sujeitos, dos agentes; e que não se constituem como um estado, mas como um processo de aprimoramento e busca permanente. Assim, segundo o autor, "a melhor definição de "escolas de qualidade' é identificá-las como 'learning schools', escolas que aprendem" (p. 13, tradução nossa ${ }^{9}$ ).

A temática da avaliação na educação infantil, apesar de ainda registrar CAMPANHA NACIONAL PELO DIREITO À EDUCAÇÃO, MIEIB. Consulta sobre Qualidade da Educação Infantil: o que pensam e o que querem os sujeitos deste direito. 2. ed. São Paulo: Cortez, Mieib, Save the Children, 2011.

8 A Consulta sobre Qualidade da Educação Infantil foi realizada pela Campanha Nacional pelo Direito à Educação e pelo Mieib, com apoio da Fundação Carlos Chagas e da Save the Children Reino Unido, durante os anos de 2004 e 2005.

9 "De ahi que la mejor definicion de las 'escuelas de calidad' es identificarlas como 'learning schools', escuelas que aprenden”. 
uma pequena produção, tem suscitado maior interesse na última década, sobretudo nos cinco últimos anos (MORO, 2013). Para Moro, duas hipóteses podem explicar esse crescimento: a própria consolidação do atendimento das crianças pequenas no âmbito da educação, normatizada e regulamentada pelos sistemas de ensino; e o lugar da avaliação no debate nacional, tal como já mencionado também no início deste artigo.

FUNDAMENTOS DA PROPOSTA DE USO DOS Indicadores da Qualidade na Educação Infantil NA AVALIAÇÃO DA POLÍTICA DE EDUCAÇÃO INFANTIL

A proposição de uma metodologia de uso dos Indicadores da Qualidade na Educação Infantil foi formulada buscando subsidiar a política educacional nos municípios, entendendo que essa proposta de avaliação pode explicitar 0 “caminho" que vai da formulação à implantação das políticas; os contextos de implantação, com seus processos e procedimentos e, ainda, seus resultados. Considerou-se para esta formulação os resultados e recomendações apresentadas pelo Monitoramento do uso dos Indicadores da Qualidade na Educação Infantil; as referências e orientações expressas no documento Educação Infantil: subsídios para construção de uma sistemática de avaliação sobre o uso dos Indicadores da Qualidade na Educação Infantil, apresentado pelo grupo de trabalho constituído em 2011 pelo MEC; a publicação $O$ uso dos Indicadores da Qualidade na Educação na construção e revisão participativas de Planos de Educação (AÇÃO EDUCATIVA, 2013a); a literatura da área e o contexto nacional de debate e normatização da política de avaliação da educação infantil.

Considerando que os dois últimos pontos foram discutidos nas seções acima, abordaremos brevemente os três primeiros aspectos antes de adentrar na proposta de uso dos Indicadores para subsidiar a avaliação na/da educação infantil.

Após ampla distribuição dos Indicadores em todo o país, foi realizado um Monitoramento $^{10}$ do uso desse material, registrando as informações de secretarias municipais de educação, creches e escolas de educação infantil, conselhos municipais de educação, fóruns de educação infantil e docentes do ensino superior com atuação voltada à educação infantil. Esse Monitoramento destacou a diversidade de usos dos Indicadores, a maior adesão de municípios 10 Esse foi um estudo realizado, em 2011, coordenado pelo MEC, Unicef, Undime, Ação Educativa e Instituto Avisa Lá, que visou identificar um panorama do uso do material a partir de monitoramento por consulta às secretarias de educação, escolas, conselhos municipais de educação, fóruns de educação infantil e outros agentes. 
de pequeno porte e a avaliação positiva sobre o material e sobre sua utilização. Identificaram-se também as distâncias entre a proposição e a execução das políticas públicas, uma vez que a implantação é sempre realizada por muitos agentes que fazem diferentes traduções dos objetivos e da metodologia instâncias de governo; instâncias decisórias na educação; escolas.

O Monitoramento evidenciou um alto índice de uso do material para além da autoavaliação das escolas, como ações voltadas à formação das equipes escolares e ao planejamento da política municipal para a educação infantil. Dentre as recomendações resultantes do Monitoramento, destacam-se: ter como referência os Indicadores e os resultados de seu Monitoramento na definição de política de Avaliação de Educação Infantil; elaborar estratégias de avaliação da gestão da educação infantil; investir mais e com urgência no envolvimento das secretarias municipais de educação na implementação da proposta dos Indicadores; divulgar amplamente a concepção de autoavaliação presente nos Indicadores para outros públicos de interesse; e ampliar os estudos que permitam aprofundar o conhecimento sobre os diferentes usos dos Indicadores apontados no estudo, buscando aprofundar as reflexões sobre as possibilidades, as aprendizagens, os obstáculos e os desafios decorrentes de tal aplicação visando recolher, nas práticas vigentes, indicações que apoiem a proposição de políticas públicas.

O grupo de trabalho ${ }^{11}$ constituído em 2011 pelo Ministério da Educação elaborou o documento denominado Subsídios para construção de uma sistemática de avaliação para a Educação Infantil, em que constam uma análise do contexto da avaliação na e da educação infantil no país, diretrizes, uma proposta metodológica preliminar e recomendações para a construção de uma sistemática de avaliação da educação infantil, como parte integrante da Política Nacional de Avaliação da Educação Básica.

${ }_{11}$ Esse grupo foi criado pela Portaria Ministerial 1.747/2011, contando com a colaboração da consultora professora dra. Sandra Maria Zákia Lian Sousa e com representantes das seguintes instituições: Instituto Nacional de Estudos e Pesquisas Educacionais Anísio Teixeira (Inep), Secretaria de Educação Básica (MEC), Fundo Nacional de Desenvolvimento da Educação (FNDE), União Nacional dos Dirigentes Municipais de Educação (Undime), Confederação Nacional dos Trabalhadores em Educação (CNTE), Associação Nacional de Pós-Graduação e Pesquisa em Educação (Anped), Movimento Interfóruns de Educação Infantil do Brasil (Mieib) e Rede Nacional Primeira Infância (RNPI). 
Propõem-se a construção de uma sistemática de avaliação da educação infantil, que compreenda a avaliação como atividade inerente à execução das políticas e programas, que a considere como processo e não como uma atividade pontual, e busque coletar subsídios para o contínuo aprimoramento do atendimento nessa etapa da educação. Essa sistemática deve, portanto, romper com uma lógica meramente formal das avaliações e estimular seu uso para induzir ações, redirecionar trajetórias, subsidiar decisões e formular políticas e planos (MINISTÉRIO DA EDUCAÇÃO, 2012, p. 11).

A partir dessas considerações, apresentam-se várias recomendações, dentre as quais se destacam duas relacionadas diretamente à proposta aqui abordada: "o GT recomenda como uma das indicações iniciais a continuidade de desenvolvimento de estudos e propostas que possam subsidiar a implantação e aprimoramento da avaliação da educação infantil”; e divulgar amplamente, por parte do MEC/SEB, "padrões de qualidade, a partir dos Indicadores da Qualidade na Educação Infantil, assegurando sistemática de envolvimento do órgão executivo do respectivo sistema de ensino" (MINISTÉRIO DA EDUCAÇÃO, 2012, p. 26).

Trata-se, pois, do reconhecimento dos Indicadores como instrumento potente de gestão da educação infantil, tanto para as unidades educacionais, uma vez que se trata de proposta de autoavaliação, quanto do seu potencial para a gestão das redes de ensino, com sua adoção como mecanismo de avaliação nas políticas públicas.

Por último, a publicação O uso dos Indicadores da Qualidade na Educação na construção e revisão participativas de Planos de Educação (AÇÃO EDUCATIVA, 2013a) se constituiu em importante referencial para a elaboração da proposta aqui apresentada. A publicação integra a iniciativa De Olho nos Planos, destinada a subsidiar o desenvolvimento de processos participativos que influenciem a elaboração/adequação e a implementação de Planos de Educação em todo o país ${ }^{12}$.

A iniciativa De Olho nos Planos, promovida por um grupo de parceiros com grande poder de convocatória no campo educacional - Undime, Unicef, Uncme, Campanha Nacional pelo Direito à Educação, Ação Educativa, Anpae, Fórum Nacional dos Conselhos Estaduais de Educação e Instituto C\&A -, visa contribuir com a ampliação da participação popular na elaboração e acompanhamento dos Planos de Educação e fortalecimento da gestão democrática na educação.

12 O novo PNE estabeleceu o prazo de um ano para que todos os estados e municípios brasileiros construam seus planos de educação com ampla participação da sociedade. 
Propondo uma articulação dos desafios referentes ao fortalecimento do planejamento público, da gestão democrática e da avaliação institucional em educação, a publicação $O$ uso dos Indicadores da Qualidade na Educação na construção e revisão participativas de Planos de Educação apresenta uma proposta metodológica inovadora de uso da coleção Indicadores da Qualidade na Educação para fins de formulação e monitoramento de políticas públicas.

Assim, tendo em vista o potencial contido no material, de contribuir com o debate da avaliação na/da educação infantil, a proposta apresentada a seguir visa apoiar as secretarias municipais de educação na definição e no acompanhamento das políticas públicas da educação infantil e, ainda, democratizar a avaliação e seu debate.

Perseguindo a metodologia participativa que é a marca da proposta que organiza e sustenta o uso dos Indicadores, tem-se como perspectiva o fortalecimento dos atores escolares e do sentido da avaliação para transformações no cotidiano e nas políticas públicas.

De sua utilização pelas unidades de educação infantil podem resultar informações sobre as condições objetivas de realização do trabalho e também apreciações dos diferentes segmentos que compõem a comunidade escolar a respeito da qualidade que se tem. A metodologia proposta para 0 uso dos Indicadores nas unidades de educação infantil ainda sugere que ao final do processo avaliativo se organize um plano de ação para a manutenção e aprimoramento do que for considerado por todos como bem equacionado e para o enfrentamento das questões entendidas como problemas ou desafios.

Tem-se, então, uma modalidade avaliativa que visa captar

$$
\begin{array}{r}
\text { aspectos da realidade educacional ainda pouco abordados, que provoquem mudanças } \\
\text { concretas no cotidiano escolar à política educacional e que mobilizem a sociedade em prol } \\
\text { da melhoria da qualidade da educação, na perspectiva de ampliar a demanda social por } \\
\text { direitos e a garantia do direito à educação (AÇÃO EDUCATIVA, 2013a,p. 8). }
\end{array}
$$

Nesse sentido, foi elaborada uma proposta metodológica visando esse "salto", de fazer a passagem da autoavaliação da unidade de educação infantil para subsidiar a política de educação infantil do município. A proposta elaborada no âmbito do grupo coordenador dos Indicadores da Qualidade na Educação Infantil foi apresentada e discutida no final de 2013 com o grupo técnico, isto é, organizações e instituições que participaram dos debates e, posteriormente, do Monitoramento desse instrumento de autoavaliação participativa. 
Tem-se como desafio conciliar a política de avaliação na e da educação infantil com a avaliação da política de educação infantil, de forma a fortalecêla e possibilitando-lhe novos sentidos (ROSEMBERG, 2013), mas sempre buscando preservar os pressupostos e princípios que nortearam a formulação dos Indicadores da Qualidade na Educação Infantil.

A proposta de uso dos Indicadores da Qualidade na Educação Infantil para subsidiar a política de avaliação da e na educação infantil nos municípios está em processo de acompanhamento em um município paulista ${ }^{13}$, com o objetivo de aprimorá-la a partir do diálogo, da realidade concreta e das experiências vividas pelos gestores e unidades da educação infantil. As reflexões, dificuldades e limitações encontradas nesse processo possibilitarão sua revisão, bem como a elaboração de materiais e subsídios para que essa proposta possa ser desenvolvida em outros municípios, além de contribuir com a construção da política nacional de avaliação da educação infantil, prevista no PNE.

ETAPAS DA PROPOSTA DE USO DOS Indicadores da Qualidade na Educação Infantil NA AVALIAÇÃO DA POLÍTICA DE EDUCAÇÃO INFANTIL

A partir das experiências e reflexões realizadas no acompanhamento dos Indicadores da Qualidade na Educação, em vários municípios paulistas e de outros estados brasileiros, foram propostas cinco etapas para a utilização dos Indicadores da Qualidade na Educação Infantil nas políticas públicas ${ }^{14}$, apresentadas a seguir.

Evidencia-se que essas etapas foram debatidas junto ao município selecionado e adequadas às condições de trabalho das unidades educacionais, bem como

${ }_{13}$ Esse uso acompanhado está ocorrendo em um município selecionado pelo grupo coordenador da iniciativa, por contemplar todos os critérios elencados para tal, sendo esses: a) viabilidade de acesso para a coleta de dados, em virtude da frequência necessária de visitas para execução conjunta do projeto; b) interesse e disponibilidade por parte da gestão municipal em participar do projeto; c) existência de atendimento às crianças pequenas, de 0 a 5 anos de idade; d) existência de uma rede de atendimento à educação infantil que contemple unidades educacionais públicas e privadas conveniadas, considerando o expressivo número de redes municipais que tem expandido o atendimento por essa via; e) número de habitantes superior a 200 mil; f) existência de Sistema Municipal de Educação; e g) adesão de ao menos 25\% das unidades de educação infantil para a realização do uso dos Indicadores e subsídio na construção da política de avaliação da educação infantil.

14 Essas etapas foram elaboradas com base nas orientações propostas em Ação Educativa, 2013a e b. 
do funcionamento e organização da rede e do sistema municipal de educação. O próprio cronograma de execução da proposta foi formulado em parceria com a comissão responsável por seu desenvolvimento no município.

\section{Etapa 1: Preparação do processo e garantia de condições concretas para 0} uso dos Indicadores

A primeira etapa de execução do projeto contempla a formação de técnicos da Secretaria Municipal de Educação (SME) e das escolas para o uso dos Indicadores, com base no debate sobre a proposta (instrumento, modo de utilização, disponibilização de resultados e uso dos resultados). Nessa etapa tem-se como objetivo acordar o processo não apenas com a equipe gestora da SME, mas também com as creches e escolas de educação infantil, "debatendo-se os sentidos na iniciativa e as condições necessárias para seu desenvolvimento, sem jamais penalizar as instituições educacionais” (AÇÃO EDUCATIVA, 2013a, p. 12 e 13).

Propõe-se nessa etapa criar um grupo de trabalho para o acompanhamento das ações. Essa comissão pode ser composta por técnicos da secretaria, representantes das comunidades escolares, representantes de instituições ligadas à defesa do direito à educação e de demais secretarias e órgãos gestores do município. O papel fundamental desse grupo de trabalho é organizar os procedimentos e acompanhar os processos, ou seja, propor a agenda de realização das ações de autoavaliação participativa para o conjunto das escolas, acompanhar sua realização, sistematizar os dados oriundos das escolas (diagnóstico e plano de ação), divulgar informações sobre o andamento do processo no município, apoiar a elaboração do Plano de Ação da SME e proceder à devolutiva para as comunidades escolares.

Para que haja condições institucionais para viabilizar essa devolutiva, bem como para que se possam efetivar os encaminhamentos necessários às demandas visibilizadas pelo processo de avaliação, é fundamental que desde o início do processo haja previsão orçamentária para tal nos instrumentos legais existentes no município, tais como Plano Plurianual (PPA), Lei de Diretrizes Orçamentárias (LDO) e Lei Orçamentária Anual (LOA).

É importante que a atuação do grupo de trabalho parta de experiências e conhecimentos já existentes no município, proporcionando um diagnóstico e mapeamento de ações e práticas já realizadas pelas unidades educacionais e da própria rede municipal com processos de avaliação e autoavaliação na educação infantil. 
Objetiva-se, nessa etapa, além da organização do processo e mapeamento das ações já realizadas, promover a formação do grupo acerca das concepções de qualidade na educação infantil.

\section{Etapa 2: Mobilização das comunidades escolares, construção do diagnóstico do município e de categorias para o tratamento das informações}

Na etapa seguinte propôs-se a aplicação dos Indicadores pelas unidades de educação infantil. Essa é uma etapa fundamental da proposta e deve, dessa forma, ser realizada com muito cuidado, desde a apresentação da proposta às unidades educacionais, sua aplicação e uso dos dados levantados. 0 grupo de trabalho constituído na primeira etapa deve se reunir com os gestores das creches e unidades educacionais para discutir as contribuições que o uso do material poderá trazer para a própria unidade, como para a política educacional do município.

Tal como evidenciado no guia O uso dos Indicadores da Qualidade na Educação na construção e revisão participativas de Planos de Educação, destaca-se a importância de um trabalho de parceria entre as unidades educacionais e a equipe da Secretaria de Educação no enfrentamento dos problemas que surgirem durante a avaliação, para que essa reflita realmente os desafios vividos pelas instituições de educação infantil (AÇÃO EDUCATIVA, 2013a).

Além do trabalho em parceria entre as unidades educacionais e os órgãos centrais, para que essa proposta reflita as reais necessidades e demandas da educação infantil, devem ser garantidas condições efetivas de participação, ou seja, que todos os participantes sejam ouvidos; sejam informados sobre os processos, eventos e reuniões que devem ocorrer em horários e locais acessíveis, e que as demandas e propostas possam ser consideradas no Plano de Ação da unidade e no material que for encaminhado à comissão responsável pelo uso dos Indicadores para subsidiar a formulação e revisão da política de educação infantil no município.

Simultaneamente à aplicação da metodologia dos Indicadores pelas escolas, será desenvolvida ${ }^{15}$ uma proposta de categorias para tratamento das informações das escolas, relacionando-as com outros dados educacionais. Nesse momento propõem-se também a criação de canais de debate com as escolas, de mecanismos/ações em resposta às demandas resultantes do processo e na criação de canais para fluxo do processo.

${ }_{15}$ A equipe da Ação Educativa desenvolverá essa base de sistematização das informações enviadas pelas unidades de educação infantil, considerando as recomendações apresentadas no documento Subsídios para construção de uma sistemática de avaliação para a Educação Infantil. 
Etapa 3: A organização e sistematização das informações do uso dos Indicadores para o diagnóstico e levantamento de propostas para a política de educação infantil

A equipe responsável pela condução do processo deverá organizar os dados disponíveis, e cada uma das creches e escolas, as informações que considerarem relevantes para a avaliação e formulação das políticas da educação infantil, decorrentes da autoavaliação proporcionada pelo uso dos Indicadores.

Pretende-se apoiar a SME na elaboração de instrumento de coleta, armazenamento e disponibilização de informações que possa ser acessado e atualizado permanentemente pelas escolas. Considerando os avanços proporcionados com as ferramentas eletrônicas, tal como a coleta dos dados do Censo Escolar (MEC/Inep), pretende-se auxiliar na construção de instrumentos que possibilitem acelerar o fluxo de informações e de encaminhamentos das ações.

Para facilitar os processos de encaminhamento e uso das informações obtidas pelas unidades de educação infantil, sugere-se a realização de quatro perguntas orientadoras, organizadas em dois eixos: 1) os problemas e propostas revelados pelo uso dos Indicadores que estão relacionados com as políticas públicas e 2) o que pode ser feito para melhorar o trabalho das escolas e ampliar o atendimento, com qualidade, à população. As perguntas têm como objetivo verificar quais das questões apresentadas dizem respeito à governabilidade da unidade educacional e quais podem contribuir com a política de educação infantil no município. As perguntas orientadoras são:

1. Quais foram os problemas encontrados?

2. Quais são as propostas para enfrentar os problemas encontrados?

3. O que pode ser feito para melhorar o trabalho realizado pela unidade educacional?

4. O que pode melhorar a política educacional, visando a ampliação e garantia de condições adequadas de atendimento? 


\section{Etapa 4: Canais para fluxo do processo, fortalecimento da gestão democrática e avaliação como processo permanente}

Para que o processo proposto dê consequência ao trabalho demandado pelas unidades de educação infantil, é necessário articular a avaliação, o planejamento e a gestão democrática, por meio da criação de canais de comunicação, execução e divulgação, que permitam a retroalimentação do processo, pela troca de informações, de apreciações e de planos de ação entre as unidades e a gestão municipal da educação.

Espera-se que a construção conjunta de metodologia de uso dos Indicadores da Qualidade na Educação Infantil para as políticas públicas se constitua como uma política permanente de avaliação e autoavaliação que se some e em sintonia com outras fontes e modalidades avaliativas presente na educação municipal.

Desse modo, não se trata apenas dos canais de debate e apoio às unidades educacionais, mas da criação e manutenção de fluxos de informação para toda a coletividade. Fluxos que, ancorados na participação, permitam o acompanhamento da execução das políticas públicas na educação infantil que tenham sido negociadas e propostas visando o atendimento universalizado e a qualidade.

São canais de fluxos do processo de autoavaliação e avaliação na/da educação infantil no município a atualização e disponibilização das informações referentes ao andamento dos processos de gestão e acompanhamento, como, por exemplo, os calendários de autoavaliação das escolas, as ações definidas pelas políticas públicas para a qualificação da oferta, as agendas da educação e as formas de participação dos diferentes agentes envolvidos nos cuidados e na proteção da infância. Também deverão ser influenciados por esse processo de avaliação da política na/da educação infantil os instrumentos legais e orçamentários previstos na gestão da política educacional, tais como o Plano Municipal de Educação, o Plano de Ações Articuladas, o Plano Diretor, o Plano Plurianual (PPA), a Lei de Diretrizes Orçamentárias (LDO), a Lei Orçamentária Anual (LOA), dentre outras específicas de cada localidade.

Pretende-se, desse modo, apoiar os gestores municipais na organização de informações e potencializar os processos participativos gerados pelos Indicadores na formulação do diagnóstico local e no monitoramento e avaliação de políticas da educação infantil, contribuindo para a explicitação de um conceito de qualidade ancorado em quatro âmbitos: 
Acesso - ampliação da oferta e estímulo à manifestação da demanda por direito à educação.

Insumos - condições objetivas de realização do trabalho educacional e pedagógico.

Processos - ações continuadas e articulação entre as políticas públicas.

Equidade - superação de desigualdades e das discriminações e valorização da diversidade.

O estabelecimento de canais de debate com as unidades educacionais é fundamental para a viabilização da avaliação que aqui se apresenta, pois se trata da construção de uma metodologia de uso dos Indicadores que se aproxime de sua proposta original, ou seja, que se organize de modo participativo e democrático no interior da gestão municipal.

Assim, o papel dos técnicos da SME e da comissão de acompanhamento ganha relevância no sentido do acompanhamento e apoio direto às unidades educacionais.

Etapa 5: A devolutiva para as unidades de educação infantil sobre os resultados do processo de avaliação participativa

Processos avaliativos comumente geram expectativas no público envolvido. Assim, será necessário organizar em conjunto com a SME, mecanismos e ações que possam responder às demandas resultantes das autoavaliações.

Responder a demandas não significa realizar prontamente o que é solicitado, mas, num debate participativo e democrático, explicitar as possibilidades, eleger prioridades, organizar ações e, ainda, divergir quando as demandas forem privatistas ou individualizadas.

Por fim, espera-se que desse processo resultem, por um lado, planos de ação para as creches e unidades de educação infantil e para a Secretaria Municipal de Educação, a partir da leitura cuidadosa dos diagnósticos e das percepções expressas pelos envolvidos e, por outro lado, informações, instrumentos e reflexões que possam subsidiar o debate sobre a política nacional de avaliação da/na educação infantil. 


\section{Quality Indicators in Children Education and the evaluation policy}

Abstract: Quality Indicators in Children Education were launched in 2009 and delivered by the Secretary of Education to all Brazilian States and municipalities. After monitoring their use in 2011/12, it was found out its great potential as a self-evaluation tool in educational units and as a support device to public policies for Education. Aiming at improving the use of Indicators and also contributing to formulate a national evaluation policy in/of Children Education as defined by National Education Plan (2014-2024), a working team constituted by MEC, UNICEF, UNDIME, and Ação Educativa delegates established a plan of use together with Indicators in a municipality of the State of São Paulo. Displayed here are the guiding premises for the plan as well as its development steps.

Key words: Children education. Evaluation. Quality. Participation. 


\section{REFERÊNCIAS}

AÇÃO EDUCATIVA. 0 uso dos Indicadores da Qualidade na Educação na construção e revisão participativas de Planos de Educação. São Paulo, 2013a.

. A construção e a revisão participativas dos Planos de Educação. São Paulo, 2013b.

BERAZA, M. A. Z. Escuelas infantiles de calidad. Editorial. RELAdEI. Revista Latinoamericana de Educación Infantil, v. 2, n. 2, p. 11-13, jul. 2013.

BRASIL. Lei 8.069 de 13 de julho de 1990. Dispõe sobre o Estatuto da Criança e do Adolescente e dá outras providências. Disponível em: 〈http://www. planalto.gov.br/ccivil_03/leis/l8069.htm〉. Acesso em: 1ํ jul. 2014.

. Lei 9.394 de 20 de dezembro de 1996. Estabelece as diretrizes e bases da educação nacional. Disponível em: 〈http://www.planalto.gov.br/ ccivil_03/leis/l9394.htm>Acesso em: 1ํ jul. 2014.

- Indicadores da Qualidade na Educação Infantil. Ministério da Educação/Secretaria da Educação Básica. Brasília, 2009.

. Conselho Nacional de Educação. Resolução no 5 de 17 de dezembro de 2009. Fixa as Diretrizes Curriculares Nacionais para a Educação Infantil. Disponível em: 〈http://portal.mec.gov.br/index.php?option=com _ docman\&task=doc_download\&gid=2298\&Itemid=>. Acesso em: 10 jul. 2014.

. Lei 13.005 de 25 de junho de 2014. Aprova o Plano Nacional de Educação - PNE e dá outras providências. Disponível em: 〈http://www. planalto.gov.br/ccivil_03/_Ato2011-2014/2014/Lei/L13005.htm> Acesso em: 1ํjul. 2014.

CAMPANHA NACIONAL PELO DIREITO À EDUCAÇÃO, MIEIB. Consulta sobre Qualidade da Educação Infantil: o que pensam e o que querem os sujeitos deste direito. 2. ed. São Paulo: Cortez, Mieib, Save the Children, 2011.

CORRÊA, B.; ANDRADE, É. Infância e vivências na educação infantil: qual o sentido das avaliações padronizadas nessa etapa educacional? Retratos da Escola, Brasília, v. 5, n. 9, p. 275-289, 2011.

FREITAS, D. N. T. A avaliação da educação básica no Brasil: dimensão normativa, pedagógica e educativa. 2005. Tese (Doutorado em Educação). Faculdade de Educação, Universidade de São Paulo, São Paulo, 2005. 
GT 7 ANPED. Moção de repúdio. 2011. Disponível em

〈http://www.anped.org.br/system/resources/W1siZilsljlwMTMvMDgvM jcvMTZfNDBfMzBfNDI5X01PX09fR1QwN190b18xXzIwMTEuZG9jll1d/ MO\%C3\%87\%C3\%830\%20GT07\%20No\%201\%202011.doc?. Acesso em: 20 ago. 2014.

MIEIB. Petição Pública do Mieib. 2011. Disponível em 〈http://www.mieib.org. br/pagina.php?menu=noticias\&codigo=161〉. Acesso em: 20 ago. 2014.

MINISTÉRIO DA EDUCAÇÃO. Subsídios para construção de uma sistemática de avaliação. Portaria n. 1.147/2011, do Ministério da Educação. Brasília, out. 2012.

MINISTÉRIO DA EDUCAÇÃO/SEB/COEDI, UNICEF, UNDIME, AÇÃO EDUCATIVA. Monitoramento do uso dos Indicadores da Qualidade na Educação Infantil: Relatório Técnico. Brasília, 2013.

MORO, C. Produção brasileira sobre avaliação em educação infantil: tendências. RELAdEl. Revista Latinoamericana de Educación Infantil, v. 2, n. 2, p 53-68, jul. 2013.

NEVES, V. F. A.; MORO, Catarina. Avaliação na educação infantil: um debate necessário. Estudos em Avaliação Educacional, São Paulo, v. 24, n. 55, p. 272302, abr./ago. 2013.

RIBEIRO, B. Indicadores da qualidade na educação infantil: potenciais e limites. Revista de Educação PUC-Campinas, Campinas, v. 18, n. 1, p. 65-74, jan./abr. 2013.

ROSEMBERG, F. Políticas de Educação Infantil e Avaliação. Cadernos de Pesquisa, v. 43, n. 148, p. 44-75, jan./abr. 2013.

SAE promove discussão sobre avaliação do desenvolvimento infantil. 5 dez. 2011. Disponível em: 〈http://www.sae.gov.br/site/?p=9623〉. Acesso em: 20 jul. 2014.

SOUSA, S. M. Z. L. Avaliação de rendimento escolar como instrumento de gestão educacional. In: OLIVEIRA, D.A.O. (Org.) Gestão democrática da educação: desafios contemporâneos. Petrópolis: Vozes, 1997, p. 264-283.

RECEBIDO: Julho de 2014.

APROVADO: Agosto de 2014. 